\title{
High coronary calcium score and post-procedural CK-MB are noninvasive predictors of coronary stent restenosis
}

\author{
Jae-Beom Lee' \\ Yun-Seok Choi ${ }^{2}$ \\ Woo-Baek Chung ${ }^{2}$ \\ Ami Kwon ${ }^{2}$ \\ Chul-Soo Park ${ }^{2}$ \\ Man-Young Lee ${ }^{2}$ \\ 'Anyang Sam Hospital, ${ }^{2}$ Division of \\ Cardiology, Department of Internal \\ Medicine, Youido St Mary's Hospital, \\ College of Medicine, The Catholic \\ University of Korea, Seoul, Korea
}

Correspondence: Yun-Seok Choi Division of Cardiology, Department of Internal Medicine, College of Medicine, The Catholic University of Korea, Yeouido St Mary's Hospital, yuksam-ro 10, Seoul 150-7|3, Korea

$\mathrm{Tel}+8223779$ | 325

Fax +82 237791374

Email cys71@catholic.ac.kr
This article was published in the following Dove Press journal:

Clinical Interventions in Aging

17 February 2017

Number of times this article has been viewed

Purpose: High coronary calcium score (CCS) and post-procedural cardiac enzyme may be related with poor outcomes in patients with coronary stent implantation.

Methods: A total of 1,072 patients (63.2\% male, mean age: $61.7 \pm 10.3$ years) who underwent coronary multi-detect computed tomography at index procedure and follow-up coronary angiography (CAG) after drug-eluting stent (DES) were divided into two groups: those with and without target lesion revascularization (TLR; $>50 \%$ reduction in luminal stent diameter or angina symptoms on follow-up CAG). The CCSs for predicting stent revascularization were elucidated.

Results: There were no significant differences between the two groups with regard to risk factors. The initial CCS was significantly higher in the TLR group $(1,102.4 \pm 743.7$ vs $345.8 \pm 51.05$, $P=0.04$ ). After adjustment of significant factors for TLR, only CCS and post-procedural creatine kinase $\mathrm{MB}$ form (CK-MB) elevation were significant predictors of coronary artery TLR. Receiver operation curve revealed that $>800$ in CCS had $69 \%$ in sensitivity and $88 \%$ in specificity about predicting the TLR.

Conclusion: High CCS with post-procedural CK-MB might be the useful predictors for TLR after DES implantation.

Keywords: coronary restenosis, drug-eluting stents, calcium, creatine kinase

\section{Introduction}

Noninvasive imaging for early detection of cardiovascular disease is actively investigated. Also, routine cardiovascular screening tests in diabetic and elderly patients are increasing. To detect coronary artery disease (CAD), various noninvasive techniques, such as the measurement of coronary calcium score (CCS), have quantitative correlation with the prevalence of CAD ${ }^{1-6}$ According to a recent metaanalysis, low-dose coronary computerized tomography (CT) showed that CCS values of $0,1-99,100-400,400-999$, and $\geq 1,000$, had 1.0, 1.9, 4.3, 7.2, and 10.8 as relative risk ratio of cardiovascular disease, respectively. ${ }^{1,2}$ The quantification of CCS has been reported to be a more reliable prognostic factor for cardiovascular disease. ${ }^{7,8}$ Highly calcified lesion was closely related with poor clinical outcomes due to stent underexpansion and edge dissection. Recently developed coronary stents show thin stent strut and high capability of conformational change, which increases the deliverability to highly calcified and angulated lesions. This kind of mechanical property has also increased the concern about stent deformation and restenosis, especially in highly calcified lesions. It must be elucidated what, other than the severity of coronary calcification, predicts stent restenosis. 
We examined whether CCS was significantly correlated with target lesion revascularization (TLR) of the coronary artery after drug-eluting stent (DES) implantation.

\section{Subjects and methods Subjects}

A total of 1,072 stable angina patients (mean age $61.7 \pm 10.3$ years, $63.2 \%$ male) diagnosed with CAD on the basis of multidetector CT (MDCT) were enrolled in this study. All of them had DESs implantation of not less than $2.5 \mathrm{~mm}$ in diameter and had been assessed by follow-up coronary angiography (CAG). We excluded patients with acute coronary syndrome, coronary stent implantation in the setting of cardiogenic shock complicating acute myocardial infarction, patients with unsuccessful stenting (defined as failure to place the stent at the desired site or to achieve a satisfactory angiographic result), patients with stenting intended primarily as a bridge to coronary artery bypass, patients with any major cardiac event (including death, myocardial infarction, bypass, repeated percutaneous transluminal coronary angioplasty, or stent vessel occlusion) during the 30 days immediately after the procedure. Above exclusion criteria may have been related to procedural complications and a lot of confounding bias so patients were not suitable for inclusion in the study.

Patients were divided into two groups. Group I included those patients who had no TLR on a follow-up CAG $(n=910)$. Group II consisted of those patients who had TLR on a follow-up CAG $(n=162)$. The mean age in group II was $62.1 \pm 9.0$ years, and the proportion of male patients was $58.6 \%(n=95)$. TLR was defined as those who need to be revascularized for the stent restenosis due to ischemic-driven symptoms or angiographic restenosis $>50 \%$ in diameter on a follow-up CAG. For all patients, MDCT was performed within a month before the initial CAG. Indications of MDCT in group I were angina $(n=564,62 \%)$, dyspnea $(n=209$, $23 \%)$ and asymptomatic $(\mathrm{n}=137,15 \%)$. Group II had angina $(n=115,71 \%)$, dyspnea $(n=30,19 \%)$ and asymptomatic $(n=17,10 \%)$ as indications.

All patients submitted written informed consent. All tests and other procedures were approved by the Institutional Review Board of The Catholic University of Korea, Seoul, Korea.

\section{Methods}

Clinical data were obtained from medical records and through interviews with all study patients. MDCT images were obtained by reconstructing the cross-sectional and multiplanar images via imaging work stations. For calcification assessment, unenhanced electrocardiographically (ECG)gated cardiac CT was performed by using a 64 detector row CT scanner (Light speed; General Electric Medical Systems, Milwaukee, WI, USA) with $2.5 \mathrm{~mm}$ section thickness ( $4 \times 2.5 \mathrm{~mm}$ collimation), pitch of $0.16,0.35$-second rotation time, $100-120 \mathrm{kV}$, and $250 \mathrm{~mA}$. In the CAG image of MDCT, iopromide (Ultravist ${ }^{\circledR}$; Berlex Laboratories Inc, New Jersey, USA) was used as a contrast medium and was intravenously infused at a rate of $5 \mathrm{~mL} / \mathrm{sec}$. A total of $70 \mathrm{~mL}$ was intravenously infused. Subsequently, $20 \mathrm{~mL}$ of saline was infused at a rate of $5 \mathrm{~mL} / \mathrm{sec}$. A bolus tracking was performed for the ascending aorta. Thus, images were obtained extending from the time point of 100 house field unit (HU) to $6 \mathrm{sec}$. The cross-sectional thickness was increased from $0.625 \mathrm{~mm}$ by degrees of $0.3 \mathrm{~mm}$. Then, images were obtained using an ECG-gated half-scan algorithm. All the patients were given oral beta blocker if they had high baseline heart rate $(>85$ beat per minute). None of the study patients need to be given additional intravenous injections of $\beta$-blockers.

\section{CAG and intervention}

Patients were given aspirin (100 mg) and clopidogrel (600 $\mathrm{mg}$ ) prior to the percutaneous coronary intervention (PCI). CAG was performed via a femoral or radial artery, for which major epicardial coronary arteries $>2.5 \mathrm{~mm}$ in length were evaluated. In the lesions, where a stenosis was observed at a magnitude of $>70 \%$ on the $\mathrm{CAG}$, the PCI was performed using various DESs: Cypher $^{\circledR}$ (sirolimuseluting stent), Taxus ${ }^{\circledR}$ (paclitaxel-eluting stent), Xience ${ }^{\circledR} /$ Promus $^{\circledR}$ (everolimus-eluting stent) and Endeavor resolute ${ }^{\circledR}$ (zotarolimus-eluting stent). Dual or triple antiplatelet therapy was continued for at least 1 year. A follow-up CAG after a mean period of $11.2 \pm 1.01$ month was performed in 1,072 patients. DESs were classified according to the stentcoating drugs and polymers. Post-procedural creatine kinase MB form (CK-MB) was measured 6 and 9 hours after the procedure. More than two times elevation from upper normal limit was defined as post-procedural CK-MB elevation. High sensitivity $\mathrm{C}$ reactive protein (hs-CRP), lipid profiles and cardiovascular risk factors were also compared.

\section{Statistical analysis}

In the comparison of the groups with and without TLR, the continuous variables were subjected to an independent $t$-test and the categorical variables were subjected to a Pearson's chi-square test or Fisher's exact test. All the data after confirmation of normal distribution were expressed as mean \pm standard deviation and the frequency ( $\%)$. In all cases, a value of 
$P<0.05$ was considered statistically significant. To analyze the factors affecting TLR, a binary logistic regression analysis was performed. Univariate variables with $P<0.20$ or known risk factor of TLR as proved in other studies were entered into the multivariate logistic models. ${ }^{9}$ A value of $P<0.05$ in the multivariate logistic analysis was considered statistically significant. To predict the occurrence of TLR based on CCS, statistical analysis was performed using the receiver operating characteristic curve. The association between CK-MB elevation and CCS was compared by chi-square test. Statistical analysis was performed using SPSS Software, Ver. 15.

\section{Results \\ Clinical characteristics}

In the baseline characteristics of 1,072 stable angina patients, the mean age was $63.1 \pm 10.1$ years and the number of males was $687(64.0 \%)$. The non-TLR group comprised 910 patients, where the male-to-female ratio was $592(56.2 \%): 318(35.8 \%)$, and their mean age was $63.4 \pm 10.1$ years. In the TLR group, there were 162 patients with a male-to-female ratio

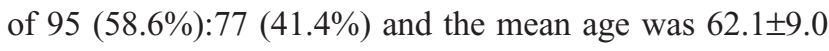
years. A comparison between the groups with and without TLR showed no significant differences in sex, age, body mass index, diabetes mellitus (DM), smoking, fasting blood sugar, hypertension, HbA1c, creatinine, CRP, total cholesterol, triglyceride, low-density lipoprotein, high-density lipoprotein, or NT-pro-BNP between the two groups (Table 1).

Angiographic data showed no significant difference in stent diameter and length between the TLR group and the non-TLR group (Table 2). Coronary stent type was significantly different between both groups. But this significance had disappeared after regression analysis (Table 2).

The mean CCS was $345.8 \pm 51.05$ in the non-TLR group and 1,102.4 \pm 743.7 in the TLR group. This difference was statistically significant ( $P=0.04$; Table 1$)$.

In univariate logistic regression analysis, parameters shown to differ significantly between the TLR and non-TLR groups included body mass index, hypertension, stent type, follow-up duration, post-procedural CK-MB elevation and calcium score. In a multivariate logistic regression analysis of these variables, the calcium score $(P=0.006$, odds ratio [OR] 1.30 [95\% CI: 1.19-1.48]) and post-procedural CK-MB elevation ( $P=0.02$, OR 1.45 [95\% CI: $1.28-1.51])$ were found to be independent predictors for TLR (Table 2). To analyze the prognostic value of the CCS for the occurrence of TLR, the receiver operating curve was used. The CCS was a more significant predictor of TLR. According to our results, at a CCS value of 800 , TLR could be predicted with a sensitivity
Table I Baseline clinical characteristics in groups with and without TLR

\begin{tabular}{|c|c|c|c|}
\hline & $\begin{array}{l}\text { Group I: } \\
\text { non-TLR } \\
(n=910)\end{array}$ & $\begin{array}{l}\text { Group 2: } \\
\text { TLR patients } \\
(\mathrm{n}=162)\end{array}$ & $P$-value \\
\hline Male sex & $592(56.2)$ & $95(58.6)$ & 0.13 \\
\hline Age (years) & $63.4 \pm 10.1$ & $62.1 \pm 9.0$ & 0.07 \\
\hline BMI $\left(\mathrm{kg} / \mathrm{m}^{2}\right)$ & $25.4 I \pm 4.00$ & $24.5 \pm 3.2$ & 0.06 \\
\hline DM & $202(22.1)$ & $34(39.0)$ & 0.11 \\
\hline HBP & $402(44.1)$ & $86(72.8)$ & 0.12 \\
\hline Smoking & $167(18.3)$ & $43(26.5)$ & 0.40 \\
\hline FBG (mg/dL) & $123.7 \pm 43.9$ & $121.6 \pm 40.2$ & 0.40 \\
\hline $\mathrm{HbAlc}(\%)$ & $6.4 \pm 1.1$ & $6.4 \pm 1.2$ & 0.53 \\
\hline Creatinine $(\mathrm{mg} / \mathrm{dL})$ & $1.07 \pm 0.6$ & $1.1 \pm 0.3$ & 0.20 \\
\hline CRP (IU) & $8.6 \pm 11.8$ & $9.3 \pm 17.4$ & 0.57 \\
\hline $\mathrm{TC}(\mathrm{mg} / \mathrm{dL})$ & $170.3 \pm 43.1$ & $165.5 \pm 44.2$ & 0.91 \\
\hline $\mathrm{TG}(\mathrm{mg} / \mathrm{dL})$ & | $36.48 \pm 80.07$ & $144.3 \pm 97.0$ & 0.12 \\
\hline $\mathrm{HDL}(\mathrm{mg} / \mathrm{dL})$ & $41.9 \pm 11.6$ & $42.3 \pm 10.3$ & 0.41 \\
\hline $\mathrm{LDL}(\mathrm{mg} / \mathrm{dL})$ & $101.9 \pm 39.2$ & $95.3 \pm 32.5$ & 0.60 \\
\hline Pro-BNP (pg/mL) & $424.9 \pm 1.6$ & $423.7 \pm 1.2$ & 0.83 \\
\hline Calcium score & $345.8 \pm 51.05$ & $\mathrm{I}, 102.4 \pm 743.7$ & $0.04 *$ \\
\hline $\begin{array}{l}\text { Post-procedural CK-MB } \\
\text { elevation }\end{array}$ & 157 (I7.2) & I 35 (83.3) & $0.02 *$ \\
\hline \multicolumn{4}{|l|}{ Stent type (lesion) } \\
\hline PES & $322(35.3)$ & $82(37.3)$ & $0.04 *$ \\
\hline SES & $816(69.6)$ & $114(51.8)$ & 0.09 \\
\hline EES & $68(5.2)$ & $9(4.1)$ & 0.23 \\
\hline ZES & $91(7.1)$ & $15(6.8)$ & 0.45 \\
\hline Stent diameter $(\mathrm{mm})$ & $3.20 \pm 0.6$ & $3.18 \pm 1.9$ & 0.84 \\
\hline Stent length $(\mathrm{mm})$ & $32.4 \pm 11.4$ & $34.8 \pm 17.2$ & 0.07 \\
\hline True bifurcation & $270(29.6)$ & $42(25.9)$ & 0.24 \\
\hline $\mathrm{AHA} / \mathrm{ACC}$ lesion B2/C & $188(20.6)$ & $32(19.8)$ & $0.8 I$ \\
\hline $\begin{array}{l}\text { Side branch occlusion } \\
(\geq 2.5 \mathrm{~mm})\end{array}$ & $19(2.1)$ & $4(2.2)$ & 0.20 \\
\hline
\end{tabular}

Notes: $* P<0.05$. apatient number ( $>2$ times elevation of the upper normal limit). Data presented as mean \pm standard deviation or $n(\%)$.

Abbreviations: BMI, body mass index; CK-MB, creatine kinase MB form; CRP, C-reactive protein; DM, diabetes mellitus; EES, everolimus eluting stent; FBG, fasting blood glucose; HBP, hypertension; HDL, high-density lipoprotein; LDL, low-density lipoprotein; PES, paclitaxel eluting stent; pro-BNP, pro B-type natriuretic peptide; SES, sirolimus eluting stent; stent type, coronary stent type; TC, total cholesterol; TG, triglyceride; TLR, target lesion revascularization; ZES, zotarolimus eluting stent; AHA, American College of Cardiology; ACC, American Heart Association.

of $69 \%$ and a specificity of $88 \%$ (Figure 1). The association with calcium score and CK-MB elevation was analyzed. The post-procedural CK-MB elevated patients (patients with high calcium score over 800 ), had a significantly high incidence of TLR rate (Table 3 ).

\section{Discussion}

The occurrence of TLR in the DES era has been markedly decreased as compared with cases of bare-metal stents. ${ }^{10}$ But TLR still remains one of the most important clinical problems related to coronary interventions. TLR mainly occurs as a result of geometric remodeling and neointima hyperplasia based on vascular pathology. ${ }^{11}$ These phenomena are also presumed to be a mechanism by which atherosclerosis occurs. ${ }^{12,13}$ 
Table 2 Logistic regression analysis of the influencing factors for prediction of TLR in lesions

\begin{tabular}{|c|c|c|c|c|}
\hline \multirow[t]{2}{*}{ Factor } & \multicolumn{2}{|c|}{ Univariate analysis } & \multicolumn{2}{|c|}{ Multivariate analysis } \\
\hline & OR $(95 \% \mathrm{CI})$ & $P$-valve & OR $(95 \% \mathrm{Cl})$ & $P$-value \\
\hline Sex & $0.89(0.67-1.19)$ & 0.37 & - & - \\
\hline Age & $1.18(0.99-1.32)$ & 0.37 & $1.13(0.94-1.19)$ & 0.49 \\
\hline BMI & $0.95(0.90-0.99)$ & $0.02 *$ & $0.92(0.35-1.24)$ & 0.48 \\
\hline DM & $1.27(0.87-1.69)$ & 0.13 & $0.84(0.18-2.22)$ & 0.39 \\
\hline HBP & $1.42(1.03-2.06)$ & $0.02 *$ & $2.11(0.78-11.9)$ & 0.16 \\
\hline Smoking & $0.83(0.59-1.19)$ & 0.24 & - & - \\
\hline FBG & $0.99(0.99-1.00)$ & 0.47 & & \\
\hline $\mathrm{HbAlc}$ & $1.10(0.89-1.12)$ & 0.91 & - & - \\
\hline Creatinine & $1.20(0.90-1.30)$ & 0.32 & - & - \\
\hline hs-CRP & $1.45(0.49-1.95)$ & 0.88 & - & - \\
\hline $\mathrm{TC}$ & $1.10(0.99-1.20)$ & 0.75 & - & - \\
\hline TG & $1.23(0.79-1.24)$ & 0.21 & - & - \\
\hline HDL & $0.99(0.98-1.01)$ & 0.60 & - & - \\
\hline LDL & $0.99(0.99-1.02)$ & 0.50 & - & - \\
\hline Stent type & & $0.04 *$ & - & 0.73 \\
\hline PES & $0.54(0.40-0.70)$ & $<0.0 I^{*}$ & $0.65(0.19-2.17)$ & 0.41 \\
\hline SES & $0.23(0.05-0.61)$ & 0.06 & $1.00(0.98-1.13)$ & 0.91 \\
\hline EES & $0.7 I(0.38-1.21)$ & 0.24 & $2.04(0.42-10.09)$ & 0.36 \\
\hline ZES & $0.97(0.12-1.28)$ & 0.13 & $3.06(0.14-67.11)$ & 0.49 \\
\hline Stent diameter & $1.017(0.86-1.19)$ & 0.84 & - & - \\
\hline Stent length & $1.028(1.01-1.03)$ & 0.11 & $1.05(1.02-1.09)$ & 0.22 \\
\hline Calcium score & $1.4 \mid(|.20-| .5 \mid)$ & $0.01 *$ & $1.30(1.19-1.48)$ & $0.01 *$ \\
\hline CK-MB elevation ${ }^{a}$ (post-procedure) & $1.60(1.33-1.70)$ & $0.02 *$ & $1.45(1.28-1.51)$ & $0.02 *$ \\
\hline
\end{tabular}

Notes: $* P<0.05$. More than two times elevation of the upper normal limit.

Abbreviations: BMI, body mass index; CK-MB, creatine kinase $\mathrm{MB} ; \mathrm{Cl}$, confidence interval; DM, diabetes mellitus; EES, everolimus eluting stent; FBG, fasting blood glucose; HBP, hypertension; HDL, high-density lipoprotein; hs-CRP, high sensitive C-reactive protein; LDL, low-density lipoprotein; OR, odds ratio; PES, paclitaxel eluting stent; SES, sirolimus eluting stent; stent type, coronary stent type; TC, total cholesterol; TG, triglyceride; TLR, target lesion revascularization; ZES, zotarolimus eluting stent.

Coronary calcification has been examined in many studies as a noninvasive surrogate by which atherosclerosis can be diagnosed and its severity can be assessed..$^{2-7}$ In addition, other studies have reported that CCS is helpful for the early detection of asymptomatic atherosclerosis. ${ }^{11,14}$ Many studies have reported that the CCS measured on CT is a significantly

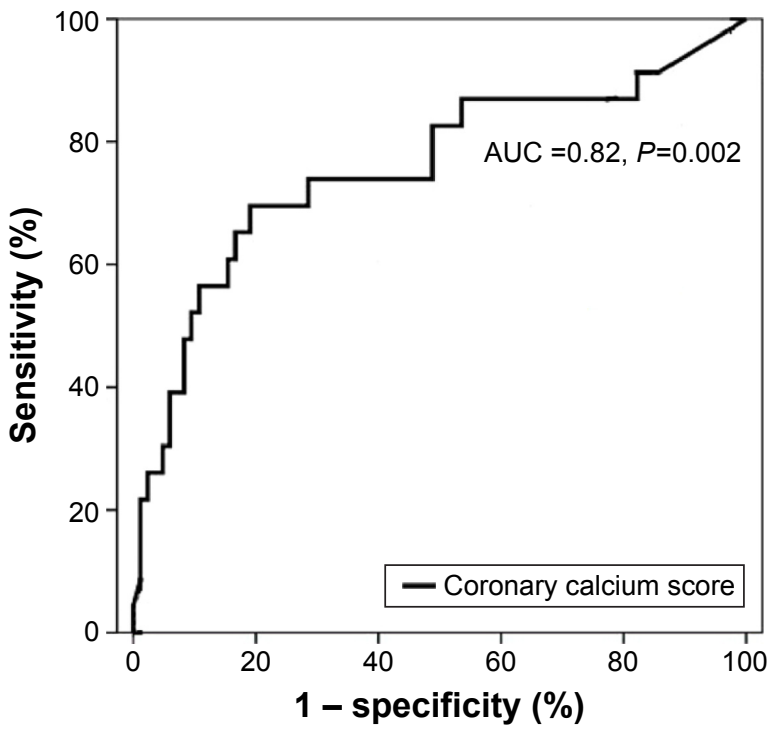

Figure I On the receiver operating curve, the calcium score was a significant predictor for TLR. A calcium score of 800 has a sensitivity of $60 \%$ and specificity of $85 \%$.

Abbreviations: AUC, area under curve; TLR, target lesion revascularization. predictive factor for the occurrence of asymptomatic and symptomatic CAD. ${ }^{15-18}$ Furthermore, the progression of coronary calcification has also been reported to be a useful indicator for treatment effects on CAD. ${ }^{19,20}$ The success rate of PCI is lower in calcified lesions of moderate or greater severity. Highly calcified lesions have a higher frequency of restenosis following $\mathrm{PCI}^{21,22}$ due to stent failure of apposition or the poor attachment of arterial wall during the $\mathrm{PCI} .{ }^{23-25}$ Our study showed that TLR patients had a significantly higher CCS than non-TLR patients. Post-procedural CK-MB elevation with high calcium score might be related with incomplete PCI, such as incomplete apposition, small branch jail and small emboli of calcified plaque. These results suggest that the CCS can be used as a predictor of TLR in patients after DES implantation.

It has been alluded that CCS is a more reliable indicator for the prediction of cardiovascular diseases than CRP. ${ }^{16}$ As MDCT has become common in clinical settings, CCS has been widely used as a noninvasive test to examine CAD. In this way, coronary artery calcification can be quantified more accurately and easily than with electron beam computerized tomography $(\mathrm{EBCT}){ }^{26}$

Parameters, such as DM, multiple stents, small final minimal luminal diameter, stent type, small coronary artery, and CRP have been reported as risk factors of TLR following DES 
Table 3 Incidence of target lesion revascularization according to coronary calcium score and post-procedural CK-MB elevation

\begin{tabular}{|c|c|c|c|c|c|c|}
\hline \multirow{2}{*}{$\begin{array}{l}\text { CK-MB } \\
\text { elevation }{ }^{\mathrm{a}}(\%)\end{array}$} & \multicolumn{2}{|c|}{ Group I, CCS $<300$} & \multicolumn{2}{|c|}{ Group II, $300 \leq$ CCS $\leq \mathbf{8 0 0}$} & \multicolumn{2}{|c|}{ Group III, CCS $>800$} \\
\hline & $\begin{array}{l}\text { TLR (-), } \\
(n=396)\end{array}$ & $\begin{array}{l}\text { TLR (+), } \\
(n=7)\end{array}$ & $\begin{array}{l}\text { TLR (-), } \\
(n=270)\end{array}$ & $\begin{array}{l}\text { TLR (+), } \\
(n=45)\end{array}$ & $\begin{array}{l}\text { TLR (-), } \\
(n=244)\end{array}$ & $\begin{array}{l}\text { TLR (+), } \\
(\mathrm{n}=\mid \mathrm{I} 0)\end{array}$ \\
\hline$(-)$ & $356(85.8)$ & $5(1.2)$ & $224(68.9)$ & $10(3.0)$ & $173(5 \mid .3)$ & $12(3.5)$ \\
\hline$(+)$ & $40(9.6)$ & $2(0.4)$ & $46(14.1)$ & $35(10.7)$ & $71(21.0)$ & $98(29.0)^{*}$ \\
\hline
\end{tabular}

Notes: $* \mathrm{P}<0.05$ compared to Groups I and II. aPatient number ( $>2$ times elevation of the upper normal limit). Data presented as $\mathrm{n}$ (\%).

Abbreviations: CCS, coronary calcium score; CK-MB, creatine kinase MB form; TLR, target lesion revascularization.

implantation. ${ }^{27-29}$ Also, DM, renal failure on hemodialysis, lesion length, reference vessel diameter, and post-interventional intravascular ultrasound (IVUS) lumen area had been reported as predictors for angiographic restenosis. ${ }^{27-29}$

\section{Conclusion}

In this study, post-procedural CK-MB and calcium score were significant predictors of TLR. This means that the CCS, as measured on MDCT prior to PCI, could be used as a noninvasive technique to predict TLR. High coronary calcium score does not directly indicate that the target lesion is heavily calcified. But it seems that the coronary lesion with high coronary calcium score should be thoroughly prepared for stent deployment. After the procedure, post-procedural CK-MB evaluation might be useful in patients with high calcium score. We suggest that the CCS reflects the multiple factors involved in TLR (the mechanical properties such as incomplete stent expansion), incomplete coverage of lesion for calcified lesions during stent deployment and the severity of coronary atherosclerosis. MDCT has broad clinical utility such as a screening tool, assessment of abnormal coronary anatomy in chronic total occlusion and cost benefit replacing the invasive angiography. However, it has concerns with radiation hazard. This study does have some limitations. No analysis was performed for the PCI through quantitative coronary anatomy or IVUS. Although many variables such as lesion characteristics, balloon inflation time, coadministrative medications are involved in the pathophysiology of TLR after DES implantation, these variables were not included in the retrospective data analysis. Calcium score measured by MDCT seems to be over-estimated. ${ }^{30}$ The current study was a retrospective, cross-sectional study at a single center. Also, there were a lot of biases to influence the clinical outcomes. Enrolled patients, in this study, were stable angina patients who took planned CAG. This meant that they had mild symptoms and severity. So, we could not say for sure that our conclusion could be applied in acute coronary syndrome patients. In this study, the frequencies of TLR and periprocedural CK elevation seem to be higher than in other studies. This might be because we enrolled patients who received follow-up angiography without exception. So asymptomatic restenosed patients were included, which was unique and different from other studies. Considering these limitations, further studies will need to verify the noninvasive surrogates to predict the stent restenosis.

\section{Acknowledgment}

This research was supported by the grant of research foundation of Internal Medicine of the Catholic University of Korea.

\section{Disclosure}

The authors report no conflicts of interest in this work.

\section{References}

1. Berman DS, Arnson Y, Rozanski A. Coronary artery calcium scanning: the agatston score and beyond. JACC Cardiovasc Imaging. 2016; 9(12):1417-1419.

2. Beigneux Y, Sablayrolles JL, Varenne O, Mas JL, Calvet D. Coronary artery calcium score improves the prediction of occult coronary artery stenosis in ischemic stroke patients. J Am Heart Assoc. 2016;5(11). pii: $\mathrm{e} 003770$.

3. Isma'eel H, Min D, Al-Shaar L, et al. Assessing level of agreement for atherosclerotic cardiovascular disease risk categorization between coronary artery calcium score and the American College of Cardiology/ American Heart Association Cardiovascular Prevention Guidelines and the Potential Impact on Treatment Recommendations. Am J Cardiol. 2016;118(10):1480-1485.

4. Schuhbaeck A, Schmid J, Zimmer T, et al. Influence of the coronary calcium score on the ability to rule out coronary artery stenoses by coronary CT angiography in patients with suspected coronary artery disease. J Cardiovasc Comput Tomogr. 2016;10(5):343-350.

5. Miller TD, Rodriguez-Porcel M. Your coronary calcium scan is positive: now what? JACC Cardiovasc Imaging. 2016;9(5):590-592.

6. Kelkar AA, Schultz WM, Khosa F, et al. Long-term prognosis after coronary artery calcium scoring among low-intermediate risk women and men. Circ Cardiovasc Imaging. 2016;9(4):e003742.

7. Breuckmann F, Olligs J, Hinrichs L, et al. Coronary artery calcium as an independent surrogate marker in the risk assessment of patients with atrial fibrillation and an intermediate pretest likelihood for coronary artery disease admitted to a German chest pain unit. Clin Cardiol. 2016; 39(3):157-164.

8. Folsom AR, Kronmal RA, Detrano RC, et al. Coronary artery calcification compared with carotid intima-meida thickness in the prediction of cardiovascular disease incidence: the multi-ethnic study of atherosclerosis (MESA). Arch Intern Med. 2008;168(12):1333-1339.

9. Basavarajaiah S, Naganuma T, Latib A, et al. Treatment of drug-eluting stent restenosis: comparison between drug-eluting balloon versus secondgeneration drug-eluting stents from a retrospective observational study. Catheter Cardiovasc Interv. 2016;88(4):522-528. 
10. Shimada Y, Kataoka T, Courtney BK, et al. Influence of plaque calcium on neointimal hyperplasia following bare metal and drug-eluting stent implantation. Catheter Cardiovasc Interv. 2006;67(6):866-869.

11. Fuchs A, Kühl JT, Chen MY, et al. Feasibility of coronary calcium and stent image subtraction using 320-detector row CT angiography. J Cardiovasc Comput Tomogr. 2015;9(5):393-398.

12. Kong L, Liu W, Yan G, et al. Poly-1-lactic acid/amorphous calcium phosphate bioabsorbable stent causes less inflammation than poly-1lactic acid stent in coronary arteries. Int J Clin Exp Med. 2014;7(12): 5317-5323.

13. Honda Y, Toyama T, Miyaishi Y, et al. Coronary artery calcification as a new predictor of non-target lesion revascularization during the chronic phase after successful percutaneous coronary intervention. Cardiovasc Interv Ther. 2014;29(4):315-323.

14. Pregowski J, Jastrzebski J, Kępka C, et al. Relation between coronary plaque calcium deposits as described by computed tomography coronary angiography and acute results of stent deployment as assessed by intravascular ultrasound. Postepy Kardiol Interwencyjnej. 2013;9(2): 115-120.

15. Tanabe K, Kishi S, Aoki J, et al. Impact of coronary calcium on outcome following sirolimus-eluting stent implantation. Am J Cardiol. 2011; 108(4):514-517.

16. Liu X, Tsujita K, Maehara A, et al. Intravascular ultrasound assessment of the incidence and predictors of edge dissections after drug-eluting stent implantation. JACC Cardiovasc Interv. 2009;2(10):997-1004.

17. Shaw LJ, Raggi P, Callister TQ, Berman DS. Prognostic value of coronary artery calcium screening in asymptomatic smokers and nonsmokers. Eur Heart J. 2006;27(8):968-975.

18. Fang HY, Lee CH, Fang CY, et al. Application of penetration device (Tornus) for percutaneous coronary intervention in balloon uncrossable chronic total occlusion-procedure outcomes, complications, and predictors of device success. Catheter Cardiovasc Interv. 2011; 78(3):356-362.

19. Raggi P, Callister TQ, Shaw LJ. Progession of coronary artery calcium and risk of first myocardial infarction in patients receiving cholesterollowering therapy. Arterioscler Thromb Vasc Biol. 2004;24(7): $1272-1277$.

20. Raggi P, Cooil B, Ratti C, Callister TQ, Budoff M. Progression of coronary artery calcium and occurrence of myocardial infarction in patients with and without diabetes mellitus. Hypertension. 2005;46(1): $238-243$.
21. Bangalore S, Vlachos HA, Selzer F, et al. Percutaneous coronary intervention of moderate to severe calcified coronary lesions: insights from the national heart, lung, and blood institute dynamic registry. Catheter Cardiovasc Interv. 2011;77(1):22-28.

22. Maffei E, Arcadi T, Zuccarelli A, et al. The impact of training on diagnostic accuracy with computed tomography coronary angiography. J Cardiovasc Med (Hagerstown). 2013;14(10):719-725.

23. Park JH, Sohn IS, Jin ES, Cho JM, Kim CJ, Lee YK. Heavy coronary calcium mimicking in-stent restenosis. Korean Circ J. 2011;41(7):421.

24. Xu K, Mintz GS, Kubo T, et al. Long-term follow-up of attenuated plaques in patients with acute myocardial infarction: an intravascular ultrasound substudy of the HORIZONS-AMI trial. Circ Cardiovasc Interv. 2012;5(2):185-192.

25. Kawaguchi R, Tsurugaya H, Hoshizaki H, Toyama T, Oshima S, Taniguchi K. Impact of lesion calcification on clinical and angiographic outcome after sirolimus-eluting stent implantation in real-world patients. Cardiovasc Revasc Med. 2008;9(1):2-8.

26. Venkitachalam L, Kip KE, Mulukutla SR, et al; NHLBI-Sponsored Dynamic Registry Investigators. Temporal trends in patient-reported angina at 1 year after percutaneous coronary revascularization in the stent era: a report from the national heart, lung, and blood institute-sponsored 1997-2006 dynamic registry. Circ Cardiovasc Qual Outcomes. 2009; 2(6):607-615.

27. Zeller T, Krankenberg H, Steinkamp H, et al. One-year outcome of percutaneous rotational atherectomy with aspiration in infrainguinal peripheral arterial occlusive disease: the multicenter pathway PVD trial. J Endovasc Ther. 2009;16(6):653-662.

28. Li Q, He Y, Chen L, Chen M. Intensive plaque modification with rotational atherectomy and cutting balloon before drug-eluting stent implantation for patients with severely calcified coronary lesions: a pilot clinical study. BMC Cardiovasc Disord. 2016;16:112.

29. Yin D, Maehara A, Mezzafonte S, Moses JW, Mintz GS, Shlofmitz RA. Excimer laser angioplasty-facilitated fracturing of napkin-ring peristent calcium in a chronically underexpanded stent: documentation by optical coherence tomography. JACC Cardiovasc Interv. 2015; 8(8):e137-e139.

30. Deprez FC, Vlassenbroek A, Ghaye B, Raaijmakers R, Coche E. Controversies about effects of low-kilovoltage MDCT acquisition on agatston calcisum scoring. J Cardiovasc Comput Tomogr. 2013;7(1):58-61.
Clinical Interventions in Aging

\section{Publish your work in this journal}

Clinical Interventions in Aging is an international, peer-reviewed journal focusing on evidence-based reports on the value or lack thereof of treatments intended to prevent or delay the onset of maladaptive correlates of aging in human beings. This journal is indexed on PubMed Central, MedLine,
Dovepress

CAS, Scopus and the Elsevier Bibliographic databases. The manuscript management system is completely online and includes a very quick and fair peer-review system, which is all easy to use. Visit http://www.dovepress. com/testimonials.php to read real quotes from published authors. 